\title{
Performa Sensor Berbasis Magneto-Impedansi pada Multilapisan $\left[\mathrm{Ni}_{80} \mathrm{Fe}_{20} / \mathrm{Cu}\right]_{N}$
}

\author{
Blasius Anggit Wicaksono, ${ }^{*}$ Nuryani, dan Budi Purnama \\ Program Studi Ilmu Fisika, \\ Program Pascasarjana, Universitas Sebelas Maret \\ Jl. Ir. Sutami No 36A Surakarta 57126
}

\begin{abstract}
Intisari
Telah dilaksanakan analisis performa sensor magnetik berbasis magneto-impedansi multilapisan $\left[\mathrm{Ni}_{80} \mathrm{Fe}_{20} / \mathrm{Cu}\right]_{N}$ pada kawat $\mathrm{Cu}$. Multilapisan adalah hasil elektrodeposisi dengan Pt (platina) sebagai elektroda. Performa sensor diamati dari hasil pengukuran nisbah magneto-impedansi dan sensitifitas sampel. Sedangkan sensor dimodifikasi berdasarkan modifikasi ketebalan lapisan konduktor dan jumlah perulangan pada sistem multilayer serta variasi bentuk geometri sensor. Hasil pengamatan memperlihatkan bahwa sensitifitas sensor MI tertinggi adalah $53,75 \% / \mathrm{mT}$ untuk sampel $\left[\mathrm{Ni}_{80} \mathrm{Fe}_{20}(800 \mathrm{~nm}) / \mathrm{Cu}(200 \mathrm{~nm})\right]_{3}$.
\end{abstract}

\begin{abstract}
Analysis of performance magnetic sensor has been carried out based magneto-impedance of $\left[\mathrm{Ni}_{80} \mathrm{Fe}_{20} / \mathrm{Cu}\right]_{N}$ multilayers on $\mathrm{Cu}$ wire. The multilayer is the result of electro-deposition methods with $\mathrm{Pt}$ (platinum) as the electrode. Sensor performance observed from the measurement of magneto-impedance ratio and sensitivity of the sample. While the sensor is modified based on the thickness of the conductor layer, the number of repetition in multilayer systems and a shape of geometric sensor. The observation shows that the highest MI sensor sensitivity is $53.75 \% / \mathrm{mT}$ to sample of $\left[\mathrm{Ni}_{80} \mathrm{Fe}_{20}(800 \mathrm{~nm}) / \mathrm{Cu}(200 \mathrm{~nm})\right]_{3}$.
\end{abstract}

KATA KUNCI: sensitivity sensor MI, $\mathrm{Ni}_{80} \mathrm{Fe}_{20}$, electro-deposition

\section{PENDAHULUAN}

Dewasa ini, terdapat beberapa ragam metode yang tersedia untuk mengindera dan mengukur kuat medan magnet seperti metode efek Hall, metode induksi, metode flux-gate, magneto resistansi dan magneto-impedansi. Metode magnetoimpedansi merupakan metode pengembangan lebih lanjut perubahan sifat kelistrikan bahan akibat medan terpasang. Dalam perkembangannya, magneto-impedansi (MI) menarik perhatian para ilmuwan mengingat sensor magneto-impedansi dapat ditumbuhkan di atas substrat fleksibel [1] dan sensitifitasnya yang sangat tinggi hingga mencapai orde pico Tesla [2].

Selanjutnya, sensor MI banyak diaplikasikan di berbagai bidang, misalnya deteksi kendaraan, geomagnetik, deteksi mata uang, sensor gerak, sensor arus, disk drive [1]. Akhirakhir ini, sensor MI ini banyak dikembangkan untuk mendeteksi sumber medan magnet bio-medikal dari tubuh manusia seperti jantung, sistem komunikasi pada neuron [3, 4].

Pada makalah ini, sensor berbasis fenomena magnetoimpedansi pada multilapisan $\left[\mathrm{Ni}_{80} \mathrm{Fe}_{20} / \mathrm{Cu}\right]_{N}$ hasil elektrodeposisi untuk frekuensi jangkauan rendah dievaluasi performanya berdasar perolehan nilai nisbah MI dan sensitifitas. Sensor dimodifikasi meliputi ketebalan lapisan konduktif

\footnotetext{
*E-MAIL: wicakgitya@gmail.com
}

(spacer $\mathrm{Cu}$ ), jumlah perulangan lapisan, dan bentuk geometri sampel.

\section{METODOLOGI PENELITIAN}

Multi lapisan tipis pada penlitian ini dihasilkan menggunakan metode elektro-deposisi dengan elektroda kawat Pt (platina). Prosedur penumbuhannya mengadopsi dengan memodifikasi pada penelitian sebelumnya [5]. Substrat yang dipakai pada penelitian berupa kawat $\mathrm{Cu}$ (tembaga) berdiameter $0,46 \mathrm{~mm}$. Substrat digunakan dibersihkan ultrasonic cleaner dalam lingkungan alkohol.

Bahan-bahan yang digunakan untuk membuat larutan elektrolit dapat dilihat pada Tabel I. Larutan elektrolit tersebut diupayakan mencapai keadaan asam yang ukuran $\mathrm{pH}$ berkisar 2,7 dengan cara diberikan beberapa tetes $\mathrm{H}_{2} \mathrm{SO}_{4} 1 \mathrm{M}$.

Gambar 1 menunjukkan skema proses elektro-deposisi lapisan $\mathrm{Ni}_{80} \mathrm{Fe}_{20}$ dan $\mathrm{Cu}$. Mula-mula proses penumbuhan lapisan $\mathrm{Ni}_{80} \mathrm{Fe}_{20}$ sebagai komponen magnetik multi-lapisan pada substrat menggunakan rapat arus $15,5 \mathrm{~mA} / \mathrm{cm}^{2}$. Setelah itu dilanjutkan proses deposisi $\mathrm{Cu}$ dengan rapat arus 8 $\mathrm{mA} / \mathrm{cm}^{2}$ sebagai lapisan konduktif pada substrat yang sebelumnya telah dilapisi lapisan magnetik $\mathrm{Ni}_{80} \mathrm{Fe}_{20}$. Kedua proses pelapisan tersebut dilakukan berulang-ulang, sehingga terbentuklah lapisan multi-lapisan/multilayer.

Pada eksperimen ini, tiga tipe sampel sensor magnetoimpedansi dievaluasi performanya. Sampel pertama dibuat 
TABEL I: Elektrolit bath untuk deposisi multi-lapisan $\left[\mathrm{Ni}_{80} \mathrm{Fe}_{20} / \mathrm{Cu}\right]_{N}$.

\begin{tabular}{lll}
\hline \hline Elektrolit & Bahan & Jumlah \\
\hline Pembentuk NiFe & $\mathrm{NiSO}_{4} \cdot 6 \mathrm{H}_{2} \mathrm{O}$ & $0,099 \mathrm{M}$ \\
& $\mathrm{FeSO}_{4} \cdot 7 \mathrm{H}_{2} \mathrm{O}$ & $0,012 \mathrm{M}$ \\
& $\mathrm{H}_{3} \mathrm{BO}_{4}$ & $0,149 \mathrm{M}$ \\
& $\mathrm{C}_{6} \mathrm{H}_{8} \mathrm{O}_{3}$ & $0,002 \mathrm{M}$ \\
Pembentuk $\mathrm{Cu}$ & $\mathrm{CuSO}_{4} .5 \mathrm{H}_{2} \mathrm{O}$ & $0,065 \mathrm{M}$ \\
& $\mathrm{C}_{6} \mathrm{H}_{12} \mathrm{O}_{6}$ & $0,002 \mathrm{M}$ \\
\hline
\end{tabular}
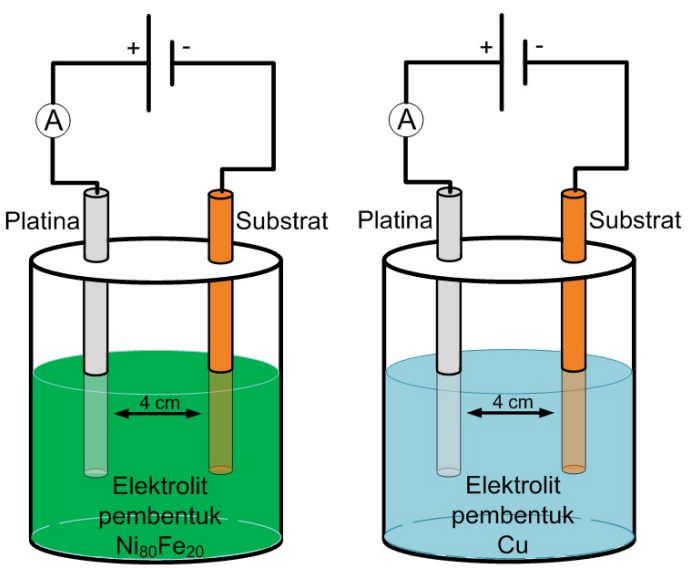

Gambar 1: Skema elektro-deposisi lapisan (a) $\mathrm{Ni}_{80} \mathrm{Fe}_{20}$ dan (b) $\mathrm{Cu}$ pada multi lapisan $\left[\mathrm{Ni}_{80} \mathrm{Fe}_{20} / \mathrm{Cu}\right]_{N}$.

dengan modifikasi ketebalan lapisan konduktif pada konfigurasi multi-lapisan $\left[\mathrm{Ni}_{80} \mathrm{Fe}_{20}(800 \mathrm{~nm}) / \mathrm{Cu}(\mathrm{y})\right]_{3}$ dengan y $=$ 200, 250, 300, dan $350 \mathrm{~nm}$. Kedua, sampel sensor dimodifikasi $\mathrm{N}$ kali jumlah perulangan lapisan pada sistem multilapisan/multilayer $\left[\mathrm{Ni}_{80} \mathrm{Fe}_{20}(800 \mathrm{~nm}) / \mathrm{Cu}(300 \mathrm{~nm})\right]_{N}$ dengan $\mathrm{N}=1$, 3, dan 5. Serta modifikasi bentuk geometri sampel, yaitu sampel dibuat kumparan seperti pada Gambar 2.

Sampel-sampel multi-lapisan tersebut dikarakterisasi nisbah magneto-impedansi (MI) dan dihitung sensitifitasnya dengan skematik pengukuran yang ditunjukkan pada Gambar 3 .

Nilai impedansi total pada pengukuran diatas adalah sumbangan nilai resistansi (R) dan reaktansi (X) dari masingmasing sampel $Z=\sqrt{R^{2}+X^{2}}$. Untuk setiap perubahan medan luar $(\mathrm{H})$, masing-masing komponen dihitung dan dihi-

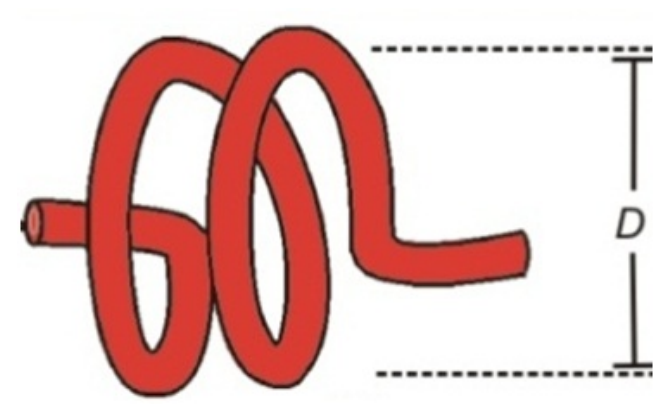

Gambar 2: Skematik sensor MI bentuk kumparan .

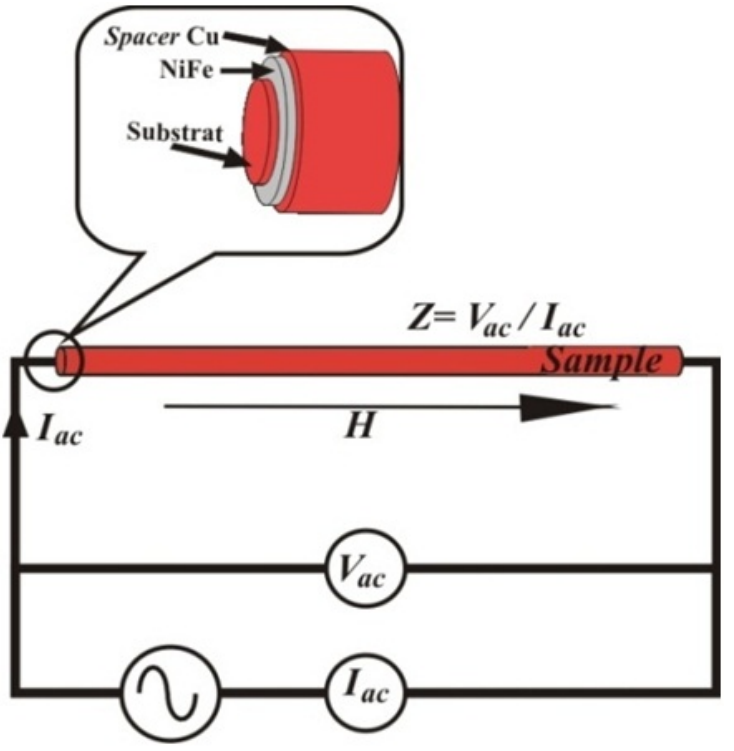

Gambar 3: Skema pengukuran magneto-impedansi.

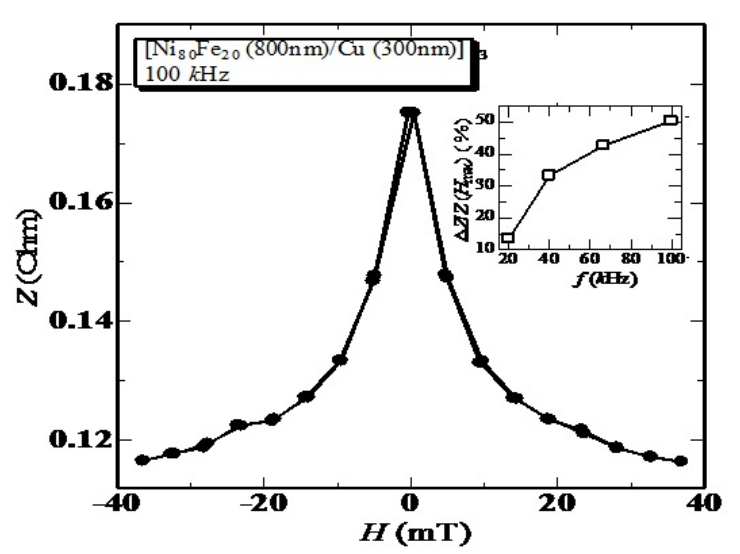

Gambar 4: Grafik impedansi listrik total $\mathrm{Z}$ sebagai fungsi medan magnet $\mathrm{H}$ atau dikenal sebagai kurva magneto-impedansi (MI) untuk multilapisan $\left[\mathrm{Ni}_{80} \mathrm{Fe}_{20}(800 \mathrm{~nm}) / \mathrm{Cu}(300 \mathrm{~nm})\right]_{3}$ pada frekuensi pengukuran $100 \mathrm{kHz}$ dan grafik nisbah/rasio MI sebagai fungsi frekuensi (inset).

tung nilai impedansi total pada medan magnet tertentu. Besar nilai nisbah MI dapat diekspresikan dengan persamaan,

$$
\frac{\Delta Z}{Z}(\%)=\frac{Z(H)-Z(H)_{\max }}{Z(H)_{\max }} \times 100 \%
$$

dengan $\mathrm{Z}(\mathrm{H})$ merupakan impedansi yang terukur ketika diberikan medan magnet luar $\mathrm{H}$, sedangkan $\mathrm{Z}(\mathrm{Hmax})$ merupakan impedansi yang terukur ketika nilai medan magnet yang diberikan maksimum [6]. Sedangkan untuk perhitungan sensitifitas sensor MI digunakan hubungan berikut,

$$
\eta=\frac{2\left(\frac{\Delta Z}{Z}\right)_{\max }}{\Delta H}
$$

dengan $\Delta \mathrm{H}$ adalah lebar penuh pada setengah maksimum kurva MI [7]. 
TABEL II: Sensitifitas Sensor MI pada frekuensi $100 \mathrm{kHz}$.

\begin{tabular}{|c|c|c|c|}
\hline Parameter & Konfigurasi & Nisbah MI (\%) & Sensitifitas $(\% / \mathrm{mT})$ \\
\hline \multirow{5}{*}{$\begin{array}{l}\text { Ketebalan Lapisan } \\
\text { Konduktif (y) }\end{array}$} & {$\left[\mathrm{Ni}_{80} \mathrm{Fe}_{20}(800 \mathrm{~nm}) / \mathrm{Cu}(\mathrm{y})\right]$} & & \\
\hline & $\mathrm{y}=200 \mathrm{~nm}$ & 118,26 & 53,75 \\
\hline & $\mathrm{y}=250 \mathrm{~nm}$ & 103,33 & 40,52 \\
\hline & $\mathrm{y}=300 \mathrm{~nm}$ & 64,95 & 14,93 \\
\hline & $\mathrm{y}=350 \mathrm{~nm}$ & 48,44 & 7,12 \\
\hline \multirow{4}{*}{$\begin{array}{l}\text { Jumlah Perulangan } \\
\text { Lapisan }(\mathrm{N})\end{array}$} & {$\left[\mathrm{Ni}_{80} \mathrm{Fe}_{20}(800 \mathrm{~nm}) / \mathrm{Cu}(300 \mathrm{~nm})\right]_{N}$} & & \\
\hline & $\mathrm{N}=1$ & 97 & 4.20 \\
\hline & $\mathrm{N}=3$ & 54 & 9,70 \\
\hline & $\mathrm{N}=5$ & 22 & 26,63 \\
\hline \multirow{3}{*}{$\begin{array}{l}\text { Bentuk Geometri } \\
\text { Sampel }\end{array}$} & {$\left[\mathrm{Ni}_{80} \mathrm{Fe}_{20}(800 \mathrm{~nm}) / \mathrm{Cu}(300 \mathrm{~nm})\right]_{3}$} & & \\
\hline & Linier $\ell=3 \mathrm{~cm}$ & 54,36 & 9,05 \\
\hline & Kumparan D =0,3 cm & 70,54 & 12,82 \\
\hline
\end{tabular}

\section{HASIL DAN PEMBAHASAN}

Gambar 4 menunjukkan tipikal grafik impedansi Z sebagai fungsi medan magnet atau yang dikenal sebagai fenomena magnetoimpedansi pada sampel multi-lapisan $\left[\mathrm{Ni}_{80} \mathrm{Fe}_{20}\right.$ $(800 \mathrm{~nm}) / \mathrm{Cu}(300 \mathrm{~nm})]_{3}$ dengan frekuensi pengukuran 100 $\mathrm{kHz}$. Grafik tersebut teramati secara jelas karakterisasi perubahan kurva impedansi saat diberikan medan magnet luar $\mathrm{H}$. Saat $\mathrm{H}=0$, nilai impedansi terukur maksimum Zmaks dan kemudian berangsur-angsur turun dengan kenaikan $\mathrm{H}$ hingga mencapai hampir jenuh pada nilai $\mathrm{Z}=0,12 \Omega$ setelah $\mathrm{H} \pm 30$ mT. Tipikal kurva semacam ini teramati juga untuk frekuensi lainnya, namun dengan nilai puncak $\mathrm{Z}_{\text {maks }}$ yang berbeda.

Nilai nisbah/rasio MI dihitung dengan Pers.(1) menggunakan data perubahan nilai impedansi akibat medan magnet yang telah diperoleh. Tipikal kurva rasio MI semacam ini juga teramati untuk frekuensi lainnya, namun dengan nilai puncak yang berbeda. Dengan menganalisa puncak-puncak kurva rasio MI tiap frekuensi, didapat bahwa nilai rasio MI meningkat seiring dengan kenaikan frekuensi. Peningkatan tersebut cenderung konstan setelah frekuensi $40 \mathrm{kHz}$. Hasil ini mengindikasi bahwa sumbangan dominan berada pada perubahan komponen reaktansi akibat medan pengimbas luar [8]. Hasil ini dapat dijelaskan sebagai berikut. Dengan meninjau sebagai sistem sederhana, ketika $\mathrm{H}_{e x}$ meningkat sepanjang arah longitudinal, magnetisasi dalam setiap domain berputar ke arah sumbu ini dan meningkatkan nilai impedansi Z. Permeabilitas maksimum tercapai ketika medan magnet eksternal statis dapat menyeimbangkan medan transversal anisotropi $\mathrm{H}_{k}$, yaitu keadaan impedansi memiliki nilai maksimum. Peningkatan lebih lanjut dari Hex mengarah ke situasi dengan rotasi magnetisasi melingkar (circular magnetization). Oleh karena itu permeabilitas circular permeability $\mu_{\varphi}$ berkurang, mencapai nilai konstan dan sangat rendah. Impedansi $\mathrm{Z}$ mengikuti perilaku yang sama. Untuk frekuensi yang relatif rendah, ketergantungan bidang impedansi tersebut diberikan untuk komponen induktif, yang hanya sebanding dengan circular permeability [9].

Dari data rasio MI yang telah diperoleh dan dengan analisis sensitifitas sensor dengan Pers.(2), key performance sensor MI dengan berbagai modifikasi pada frekuensi pengukuran 100 $\mathrm{kHz}$ dapat dilihat pada Tabel II. Teramati dengan jelas bahwa kenaikan nisbah MI selaras dengan kenaikan sensitifitas sensor.

Dari hasil penelitian, setiap variasi pada masing-masing konfigurasi sampel yang telah dilakukan memiliki tingkat sensitifitas yang berbeda. Pada modifikasi ketebalan lapisan konduktif didapat sensitifitas sensor MI tertinggi 53,75\%/mT di ketebalan $200 \mathrm{~nm}$, yaitu di ketebalan paling tipis konduktif. Modifikasi ini menghasilkan sensitifitas sensor MI semakin menurun seiring dengan penambahan ketebalan koduktif. Efek ini dapat dijelaskan dengan teori MI yang terjadi pada sistem multilapisan yang terealisasi pada konduktur kawat silinder. Efek ini dikarenakan adanya perbedaan resistansi antara lapisan magnetik dan non-magnetik. Ketika nilai ketebalan magnetik meningkat maka resistansi dari lapisan ini mengalami penurunan. Ketika lapisan magnetik ini terus diperbesar maka resistansi dari lapisan magnetik ini akan mendekati nilai resistansi dari lapisan non-magnetik.

Sedangkan pada modifikasi perulangan lapisan, sensitifitas sensor MI tertinggi $26,63 \% / \mathrm{mT}$ pada $\mathrm{N}=5$, yaitu pada jumlah perulangan lapisan terbanyak. Kenaikan jumlah perulangan lapisan akan meningkatkan komponen riil dan imajiner impedansi sampel. Ketika jumlah perulangan lapisan dimodifikasi, nilai reaktansi yaitu bagian imajiner pada impedansi total sampel mengalami perubahan lebih drastik dibandingkan komponen riil. Akibatnya, nilai terukur nisbah MI ataupun sensitifitas sensor MI untuk sampel dengan $\mathrm{N}=5$ terbesar dibandingkan sampel lainnya.

Ekspresi lain sensitifitas sensor MI dengan modifikasi bentuk geometri sampel, yaitu membandingkan sampel dengan bentuk kawat linear dengan bentuk kawat solenoid. Perubahan bentuk dari kawat menjadi solenoid juga meningkatkan sensitifitas sensor. Pada solenoid didapatkan sensitifitas sensor hingga mencapai $12,82 \% / \mathrm{mT}$. Pada modifikasi ini mengenai peningkatan induktansi eksternal terhadap struktur geometri sampel. Adanya peningkatan tersebut dikaitkan dengan interaksi magnetik komplek (fluk magnetik) dan 
mekanisme magnetisasi. Fluk magnetik tersebut dalam masing-masing arah garis lurus longitudinal dan ternsversal akan menghubungkan antara satu sama lainnya dengan saling menginduksi (self-induction).

\section{SIMPULAN}

Performa sensor magnetik berbasis magneto-impedansi multilapisan $\left[\mathrm{Ni}_{80} \mathrm{Fe}_{20} / \mathrm{Cu}\right]_{N}$ pada kawat $\mathrm{Cu}$ telah diuji melalui nisbah magneto impedansi dan sensitifitas. Sensor magnet berupa multilapisan hasil elektrodeposisi menggunakan elektrode Pt (platina). Sensor divariasi berdasarkan ketebalan lapisan konduktor dan jumlah perulangan pada sistem multilayer serta variasi bentuk geometri sensor. Hasil eksperimen menunjukkan bahwa sensitifitas sensor magnet tertinggi diperoleh sebesar $53,75 \% / \mathrm{mT}$ untuk sampel $\left[\mathrm{Ni}_{80} \mathrm{Fe}_{20}(800 \mathrm{~nm}) / \mathrm{Cu}(200 \mathrm{~nm})\right]_{3}$.
[1] P. Ripka, Magneti Sensors and Magnetometers (Artech House, Inc. London, 2001).

[2] T. Uchiyama, et al., IEEE Transactions on Magnetics, 48, 38333839 (2012).

[3] J. Devkota, et al., Journal of Applied Physics, 49, 4060-4063 (2013).

[4] T.E. Wang, et al., Biosensors and Bioelectronics, 58, 338-344 (2014).

[5] M. Amiruddin, Utari, and B. Purnama, Jurnal Fisika dan Ap- likasinya, 10(2), 95-98 (2014).

[6] M. Knobel, M. Vazquez, and L. Kraus, Handbook of magnetic materials (Elsevier Science B.V 15, 1-69, 2003).

[7] L.H. Tuan, N.T. Huy, and P.T. Huy, Journal of Physics, 187(1), 1-5 (2009)

[8] A. Chaturvedi, et al., Science Jet, 3, 1-4 (2014).

[9] M. Knobel, and K.R. Pirota, Journal of Magnetism and Magnetic Materials, 242, 33-40 (2002). 